\title{
One-Pot Multi-Reaction Processes: Synthesis of Natural Products and Drug-Like Scaffolds
}

\author{
Ewen D. D. Calder, Mark W. Grafton, Andrew Sutherland* \\ WestCHEM, School of Chemistry, The Joseph Black Building, University of Glasgow, Glasgow, G12 8QQ, UK \\ Fax +44(141)3304888; E-mail: Andrew.Sutherland@glasgow.ac.uk
}

Received: 13.11.2013; Accepted: 23.12.2013

License terms: (c) (P)

Abstract: One-pot multi-reaction processes involving Overman rearrangements, metathesis cyclizations, and Diels-Alder reactions have been developed for the rapid and efficient synthesis of aminosubstituted carbocyclic and heterocyclic compounds. This account describes the development and optimization of these processes, as well as their applications in the synthesis of natural products and drug-like scaffolds.

1 Introduction

2 A One-Pot Overman Rearrangement and Ring-Closing Metathesis Reaction

$2.1 \quad$ Scope and Limitations

2.2 Applications of the One-Pot Two-Step Process

2.3 A Directed Overman Rearrangement and Ring-Closing Metathesis Reaction Process

3 A One-Pot Three-Step Ruthenium(II) Tandem Catalytic Process

3.1 Development and Scope

3.2 A Microwave-Mediated One-Pot Three-Step Process

4 A One-Pot Three-Step Process Involving a Ring-Closing Enyne Metathesis and a Diels-Alder Reaction

4.1 Synthesis of Substrates

4.2 An Unexpected Hydrogen-Bonding-Directed Diels-Alder Reaction

4.3 Application of the Synthesis for C1-Amino-Substituted Indanes and Tetralins

4.4 Development of a Two-Pot Reaction Process

5 Conclusions

Key words: Overman rearrangement, metathesis, Diels-Alder reaction, catalysis, transition metals, multistep reaction

\section{$1 \quad$ Introduction}

In the push for greener and more-efficient methods of synthesizing important organic compounds and their intermediates, the need to isolate and purify each product in the synthetic route is time consuming and is responsible for most of the waste generated. Consequently, an increasing number of syntheses involve one-pot processes. These can be broadly separated into two categories: domino or cascade reactions in which the substrates are designed to undergo several reactions without the addition of further reagents or catalysts, and multistep multi-reaction processes in which reagents and catalysts are added during the process as needed to generate the target product. $^{1-3}$

SYNLETT 2014, 25, 1068-1080

Advanced online publication: 10.02.2014

DOI: 10.1055/s-0033-1340683; Art ID: ST-2013-A1054-A

(c) Georg Thieme Verlag Stuttgart · New York
Such processes eliminate the need for isolation, handling, and purification of intermediates, and they generally form the target compounds efficiently and with minimal waste.

The use of one-pot multi-reaction processes, termed 'pot economy' by Clarke and co-workers, ${ }^{4}$ has been very effective in preparing medicinally important compounds and natural products. ${ }^{4,5}$ The power of this approach has been elegantly demonstrated by Hayashi and Umemiya in their three-pot synthesis of prostaglandin $\mathrm{E}_{1}\left(\mathrm{PGE}_{1}\right)$ methyl ester (Scheme 1). ${ }^{6}$ The prostaglandin skeleton 1 was constructed in $81 \%$ yield by a one-pot reaction involving an asymmetric organocatalytic Michael reaction, an intramolecular Henry reaction, and a Horner-WadsworthEmmons (HWE) reaction. Of the eight possible diastereomers, only three were formed in a ratio of 76:17:7. Stereoselective reduction of the ketone and a second one-pot multistep process involving functional group transformations of the cyclopentyl ring completed the total synthesis of $\mathrm{PGE}_{1}$ methyl ester in $14 \%$ overall yield.
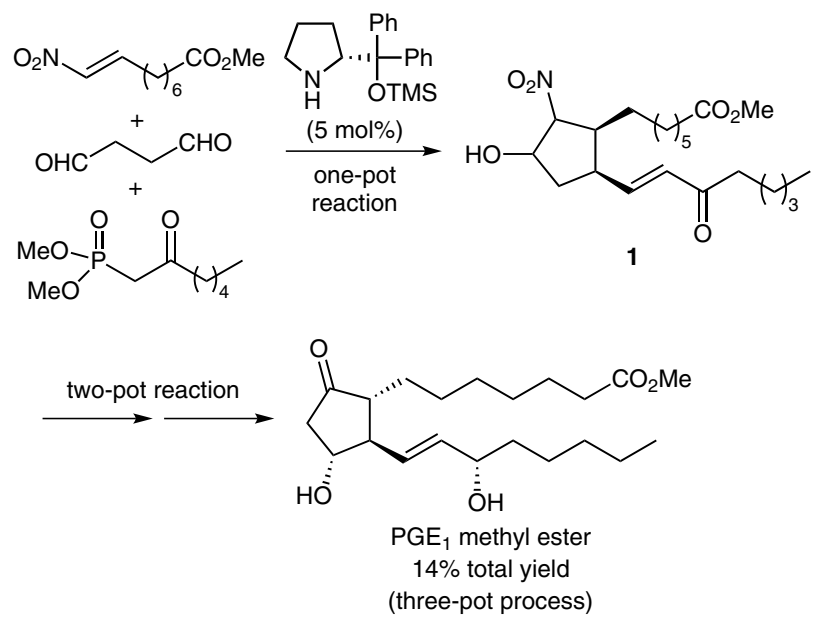

Scheme 1 Three-pot total synthesis of $\mathrm{PGE}_{1}$ methyl ester

Our contribution to the development of one-pot multireaction processes was born from our frustration in having to optimize trivial synthetic steps during early projects within the Sutherland group. One of the first processes that we discovered was an ether-directed palladium(II)catalyzed Overman rearrangement ${ }^{7}$ that permitted the diastereoselective synthesis of anti-vicinal amino alcohols. ${ }^{8}{ }^{89}$ Mechanistic studies with a range of substrates in non-coordinating solvents showed the MOM ether to be the most effective directing group, with both oxygen at- 
oms involved in complexation to the palladium(II) catalyst (Scheme 2).

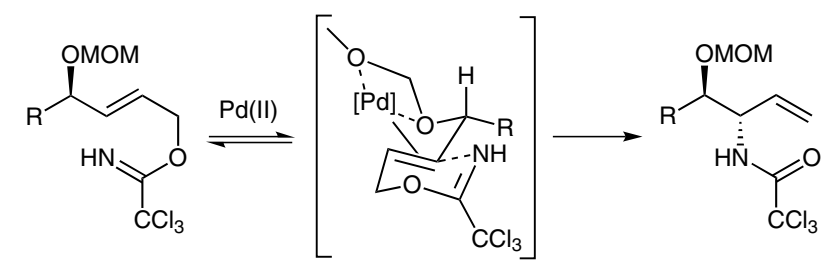

Scheme 2 Ether-directed palladium(II)-catalyzed Overman rearrangement

On optimization of this process, we used the anti-vicinal amino alcohols in efficient preparations of a range of nat- ural products, including $\beta$-hydroxy and $\gamma$-hydroxy $\alpha$-amino acids, ${ }^{10}$ the alkaloid (+)-monanchorin, ${ }^{11}$ and amino alcohols such as clavaminol $\mathrm{H}$ and D-erythro-sphinganine. ${ }^{12,13}$ However, in completing some of these routes, we were spending more effort in optimizing trivial steps rather than the key transformations. ${ }^{14}$ A good example of this was our synthesis of the alkaloid $\alpha$-conhydrine (5; Scheme 3). ${ }^{15}$ After optimizing the MOM ether directed Overman rearrangement to give the protected anti-vicinal amino alcohol 2, our aim was to functionalize the amine with an alkene moiety that could then undergo a ring-closing metathesis (RCM) reaction to give the piperidine ring of $\alpha$-conhydrine (5). Our initial plan was to alkylate the trichloroacetamide 2 with 4-bromobut-1-ene. However, various attempts with different bases and the addition of

\section{Biographical Sketches:}
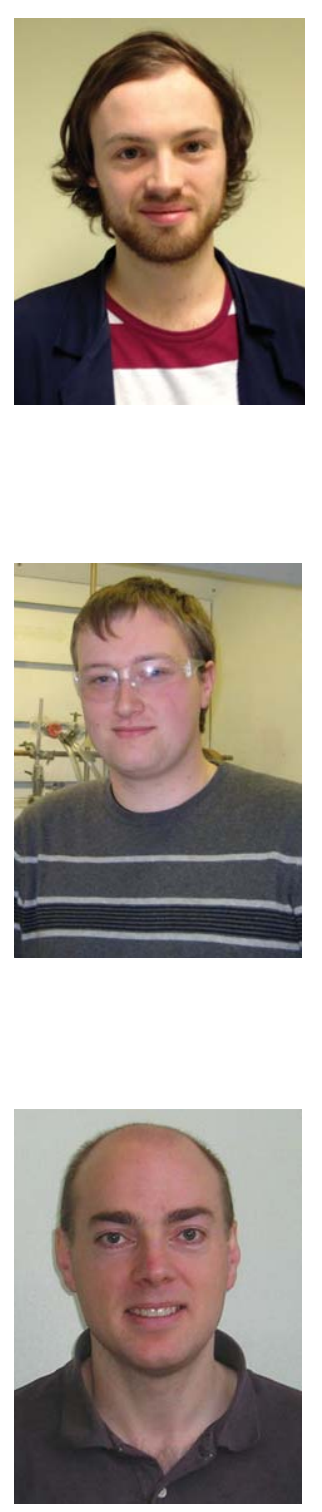

Ewen Calder was born in 1989 in Liverpool, England. He graduated with a MChem degree in chemistry from the University of St Andrews after carrying out an industrial placement at Chroma Therapeutics, working on the synthesis of new oncology and antiinflammatory drug targets.

Mark Grafton was born in 1987 in Kilmarnock, in the West of Scotland. He graduated with a MSci degree in chemistry from the University of Strathclyde, winning the Pfizer Prize for Best Organic Student in his third year. He carried out an industrial placement with Pfizer, which focused on the

Andrew Sutherland was born in 1972 in Wick, in the North of Scotland. After graduating with a BSc Honours degree in chemistry from the University of Edinburgh in 1994, he undertook a $\mathrm{PhD}$ at the University of Bristol under the supervision of Professor Christine Willis. In 1997, he joined the research group of Professor John Vederas at the
At the University of St Andrews, he conducted research projects on pseudorotaxane synthesis with Professor Douglas Philp, and on the catalytic generation of azolium and ammonium enolates in the group of Professor Andrew Smith. Since 2011, he has been working toward his

development of flow chemistry for the rapid synthesis of drug targets. In his final year, he conducted a research project under the supervision of Professor John Murphy, studying the in situ preparation and reactivity of new N-heterocycle carbenes. Since 2010, he has been part of the Sutherland

University of Alberta, where he studied diaminopimelate metabolism for the design of novel antibiotics. He then returned to the University of Bristol as a junior research fellow, working with Professor Timothy Gallagher on the design and synthesis of nicotinic acetylcholine receptor agonists. In January 2003, he was appointed to a lectureship in
$\mathrm{PhD}$ at the University of Glasgow under the supervision of Dr. Andrew Sutherland, studying novel onepot multi-reaction processes and their applications in total synthesis of benzo[c]phenanthridine alkaloid natural products.

group at the University of Glasgow, working toward his $\mathrm{PhD}$ which is focused on the development of one-pot multi-reaction processes involving hydrogen bondingdirected Diels-Alder reactions for the synthesis of guanidine alkaloids.

the School of Chemistry at the University of Glasgow, and in 2008 he was promoted to the position of senior lecturer. His research group's interests involve the development of new synthetic methods for the synthesis of chiral, biologically active, and medicinally important compounds. 
sodium iodide all merely produced reduced amounts of the starting material. Similar results were obtained with a tert-butoxycarbonyl derivative and with the unprotected amine. Eventually, an acylation strategy with but-3-enoyl chloride gave diene $\mathbf{3}$, which then readily underwent a facile RCM reaction. While this approach did complete the total synthesis, further work was required to optimize the penultimate step, the reduction of the $\delta$-lactam.<smiles>C=C[C@H](NC(=O)C(Cl)(Cl)Cl)C(CC)OOC</smiles><smiles>O=[N+]([O-])OCCO[Na]</smiles><smiles>C=CCC(=O)N[C@@H](C=C)C(CC)OC</smiles><smiles>CCC(OC)[C@H]1C=CCC(=O)N1</smiles>

$$
\begin{aligned}
& \text { 1. } \mathrm{H}_{2}, \mathrm{Pd} / \mathrm{C}, \mathrm{EtOAc} \\
& \text { 2. } \mathrm{BH}_{3} \cdot \mathrm{THF} \\
& \underset{\text { 3. } 6 \mathrm{M} \mathrm{HCl}}{ } \\
& \hline \begin{array}{c}
42 \% \text { (over } \\
\text { three steps) }
\end{array}
\end{aligned}
$$<smiles>CCC(O)[C@H]1CCCCN1</smiles>

4

5
Scheme 3

It was this particular project that led us to consider whether compounds could be designed to undergo an Overman rearrangement followed directly by an RCM reaction without any intermediate step. We also considered the possibility of whether both reactions, each using a different transition-metal catalyst, might be conducted in the same reaction vessel. This account describes our efforts to develop and optimize one-pot multi-reaction processes involving the Overman rearrangement and metathesis reactions. We discuss the extension of these processes to include additional steps, such as Kharasch cyclizations or Diels-Alder reactions. We also show how the synthetic products generated from these one-pot multi-reaction processes have been used to provide rapid access to natural products and privileged structures for medicinal chemistry.

\section{A One-Pot Overman Rearrangement and Ring-Closing Metathesis Reaction}

\subsection{Scope and Limitations}

Our first targets for a one-pot Overman rearrangement and RCM reaction process were cyclic allylic trichloroacetamides, such as 7 , which we believed might be formed from allylic trichloroacetimidates $\mathbf{6}$ bearing an alkene side chain (Scheme 4). We felt that easy access to compounds such as $\mathbf{7}$ would be of general interest, as these have been used as synthetic intermediates for a range of processes, including directed oxidations, ${ }^{16,17}$ ruthenium- and nickelmediated radical cyclizations for the preparation of bicyclic $\gamma$-lactams 8 and $\mathbf{9}$, respectively, ${ }_{18,19}$ and ring-closing iodinations to give bicyclic 4,5-dihydro-1,3-oxazoles such as $\mathbf{1 0} .^{20}$

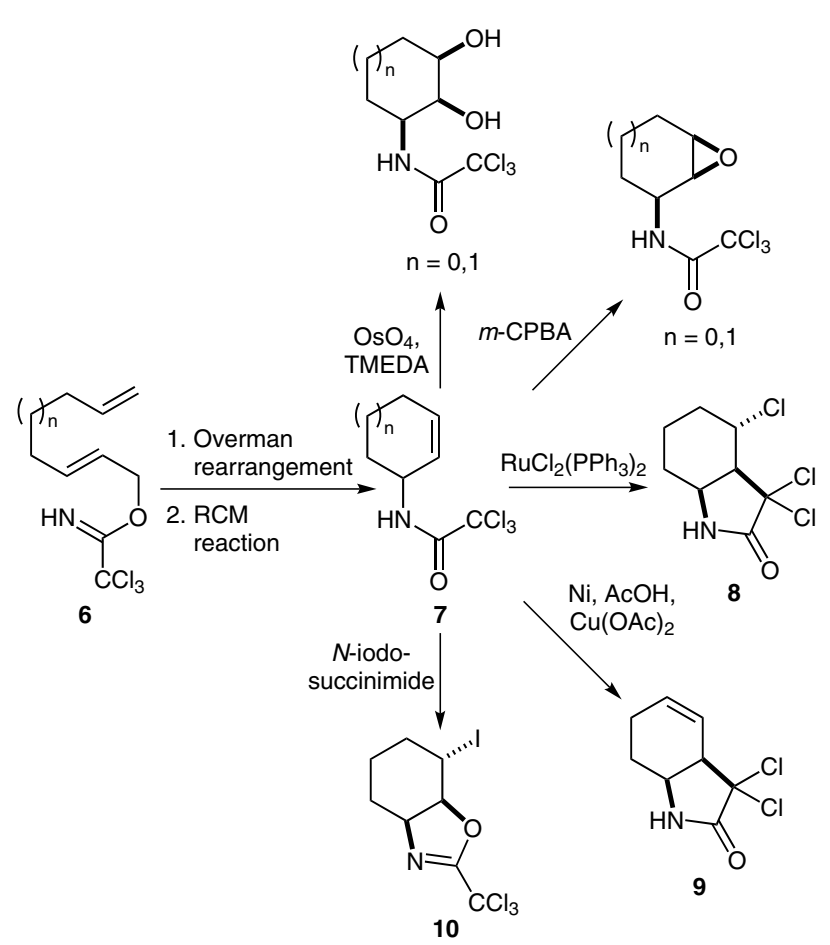

Scheme 4

An important aspect of this program of research was to demonstrate that the substrates for our one-pot multi-reaction processes could be easily and efficiently prepared from commercially available starting materials. A threestep route to the required alkene-derived allylic alcohols was devised that used a one-pot multi-reaction process (Scheme 5). ${ }^{21}$ Commercially available alcohols such as hex-5-en-1-ol were subjected to a one-pot Swern oxidation and HWE reaction to give the corresponding $(E)-\alpha, \beta$ unsaturated esters in $69-90 \%$ yield. $^{22}$ The high yields from this one-pot two-step process arose from a combination of not having to isolate the volatile aldehyde intermediates and the mild Masamune-Roush conditions for the HWE reaction. ${ }^{23}$ Although other organophosphorus alkene-forming reactions were investigated for the synthesis of the $\alpha, \beta$-unsaturated esters, only the HWE reaction consistently gave the $E$-isomers as the sole products. Reduction of the esters by using 2.2 equivalents of DIBAL$\mathrm{H}$ gave the $(E)$-allylic alcohols in high yields (81-100\%).

Development of our first one-pot multi-reaction process began with the conversion of (2E)-octa-2,7-dien-1-ol (11) into the corresponding allylic trichloroacetimidate 12 by treatment with trichloroacetonitrile and a catalytic amount of DBU (Scheme 6). ${ }^{21}$ At the end of the reaction, and without purification, the allylic trichloroacetimidate $\mathbf{1 2}$ was subjected to an Overman rearrangement in the presence of bis(acetonitrile)palladium(II) chloride (10 mol\%). After three hours, Grubbs' first-generation catalyst (10 mol\%) was added. When the reaction was shown to be complete by TLC and NMR spectroscopy, purification 


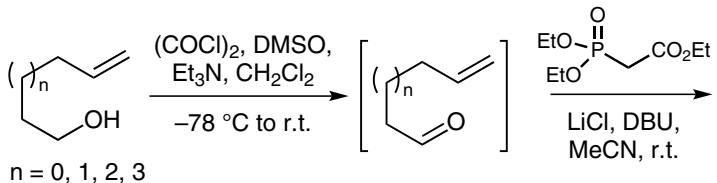

$\mathrm{n}=0,1,2,3$

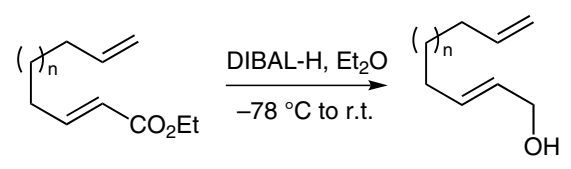

$\mathrm{n}=0(77 \%)$

$\mathrm{n}=1(69 \%)$

$\mathrm{n}=2(72 \%)$

$\mathrm{n}=3(90 \%)$

$$
\begin{aligned}
& n=0(82 \%) \\
& n=1(87 \%) \\
& n=2(100 \%) \\
& n=3(81 \%)
\end{aligned}
$$

Scheme 5

gave the cyclic allylic amide $\mathbf{1 4}$ in $89 \%$ yield over the three steps. Slightly higher yields were obtained by using either Grubbs' second-generation catalyst or the Hoveyda-Grubbs second-generation catalyst to effect the RCM step. Note that although these catalysts were slightly more efficient in producing 14, most applications of this onepot process use the significantly less-expensive Grubbs' first-generation catalyst.

Although we were delighted by the outcome of this first one-pot multistep process, we wanted to show that a domino-type procedure could be performed by adding both palladium(II) and ruthenium(II) catalysts simultaneously to the allylic trichloroacetimidate 12. However, this gave the allylic trichloroacetamide $\mathbf{1 3}$ exclusively. This is probably the result of the known process of deactivation of RCM catalysts by acetonitrile, which was released from the palladium(II) catalyst. ${ }^{24}$ We briefly studied catalysts such as palladium(II) chloride for the rearrangement step, and although this did lead to the preparation of $\mathbf{1 4}$ by a one-pot domino-type process, the overall process was slower and less efficient because of the lower solubility of the catalyst.

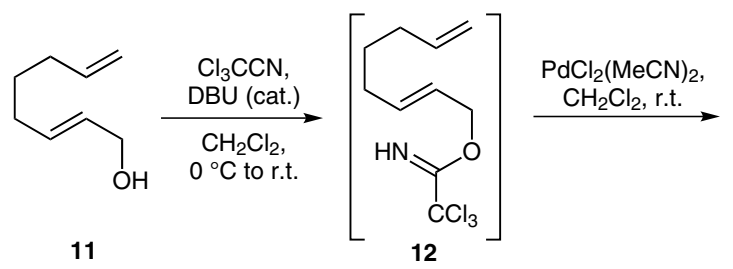<smiles>C=CCCCC(C)NC(=O)C(C)(C)C</smiles>

13

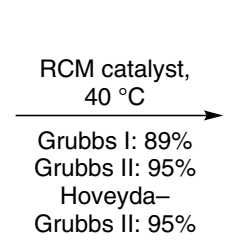

Grubbs II: $95 \%$<smiles>O=C(NC1C=CCCC1)C(Cl)(Cl)Cl</smiles>

14
Scheme 6

Next, we examined the scope of the two-step process using the stepwise addition of catalysts for the preparation of other ring sizes (Figure 1). ${ }^{21}$ Both the cyclopentene and cycloheptene analogues were prepared in high yields under similar conditions to those used for cyclohexene 14. Application of the one-pot process with Grubbs' first-generation catalyst in the preparation of the cycloctene analogue gave only the rearrangement product. However, a lower reaction concentration $(0.0013 \mathrm{M})$ and the use of Grubbs' second-generation catalyst at a higher loading (20 mol\%) gave this challenging target in $62 \%$ overall yield.<smiles>O=C(NC1C=CCC1)C(Cl)(Cl)Cl</smiles>

$84 \%$<smiles>O=C(NC1C=CCCC1)C(Cl)(Cl)Cl</smiles>

$89 \%$<smiles>O=C(NC1C=CCCCC1)C(Cl)(Cl)Cl</smiles>

$93 \%$<smiles>O=C(NC1C=CCCCCC1)C(Cl)(Cl)Cl</smiles>

$62 \%^{\mathrm{a}}$
Figure 1 Products of the two-step process with stepwise addition of

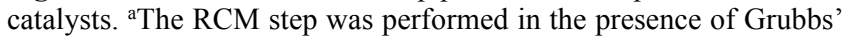
second-generation catalyst

Because we wanted to use the one-pot, two-step process for the synthesis of natural products, we decided to develop an asymmetric version. Richards and co-workers had reported the preparation of chiral palladium(II) catalysts, ${ }^{25}$ such as $(S)$-COP-Cl (15), and, in collaboration with Overman's group, had shown that these catalysts could be used in an efficient rearrangement of allylic trichloroacetimidates with excellent enantiomeric excesses. ${ }^{26}$ Use of commercially available $\mathbf{1 5}$ in our one-pot process gave the $(S)$-cyclohexene amide $(\mathrm{n}=1)$ in $88 \%$ ee and $90 \%$ yield over the three steps (Scheme 7). ${ }^{21}$ Similar levels of asymmetric induction for the preparation of the opposite enantiomer were obtained by using $(R)-\mathrm{COP}-\mathrm{Cl}$. More recently, the COP-Cl catalysts have been used for the asymmetric synthesis of rings of other sizes; $;{ }^{27}$ for example, the $(S)$-cyclopentene analogue $(\mathrm{n}=0)$ was obtained in $88 \%$ yield and $92 \%$ ee (Scheme 7 ).

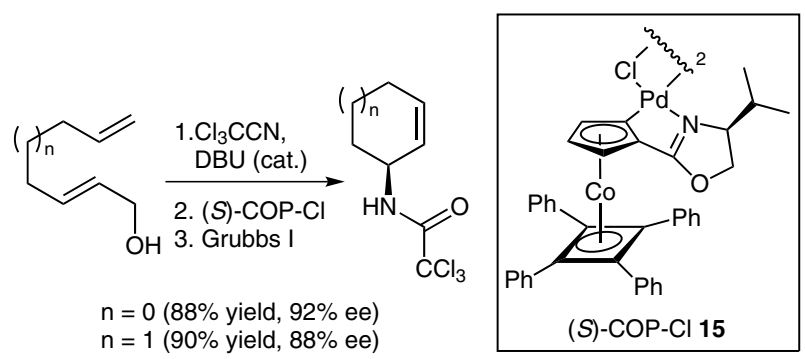

Scheme 7

\section{2 \\ Applications of the One-Pot Two-Step Pro- cess}

The first application of the one-pot two-step process was a short asymmetric synthesis of the tropane alkaloid $(+)-$ physoperuvine (19; Scheme 8). ${ }^{28}$ An asymmetric Overman rearrangement and an RCM reaction gave cycloheptyl amide 16 in $82 \%$ yield and $84 \%$ ee. A single 
recrystallization of $\mathbf{1 6}$ improved the enantiomeric excess to $>99 \%$. A switch of the amine-protecting groups followed by methylation gave carbamate 17 in $84 \%$ yield over the two steps. Allylic oxidation with tert-butyl hydroperoxide and selective hydrogenation of the alkene in the presence of the ketone gave the oxo carbamate 18. Finally, trifluoroacetic acid mediated removal of the tertbutoxycarbonyl protecting group resulted in cyclization to complete a total synthesis of (+)-physoperuvine (19).
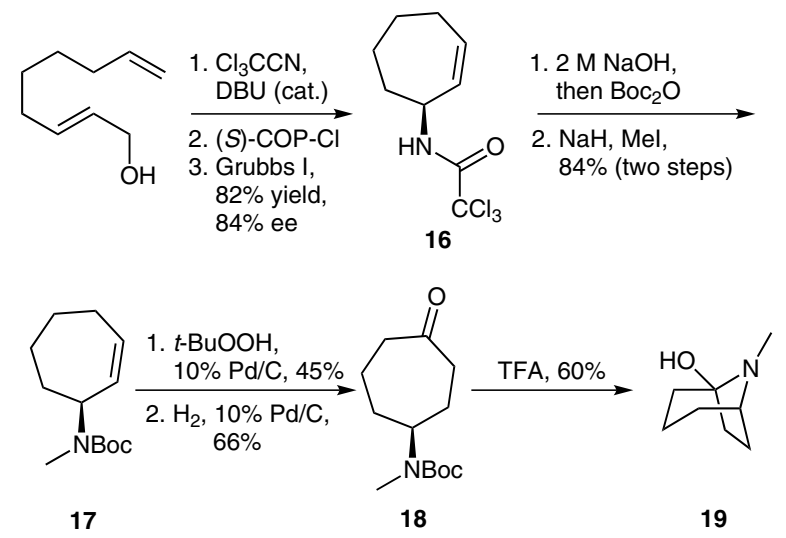

Scheme 8

The ease of functionalization of the products generated by the one-pot two-step process was further demonstrated by the rapid synthesis of dihydroconduramines, which can mimic oligosaccharides and act as inhibitors of glycosides. ${ }^{29}$ Initially, the $(S)$-cyclohexene amide generated from the asymmetric one-pot process (Scheme 7) was treated with $N$-iodosuccinimide to give the corresponding 4,5-dihydro-1,3-oxazole $\mathbf{2 0}$ as a single stereoisomer (Scheme 9). ${ }^{20}$ Elimination of hydrogen iodide and hydrolysis of the 4,5-dihydro-1,3-oxazole under mild conditions gave the allylic alcohol 21 in $60 \%$ yield over the three steps.
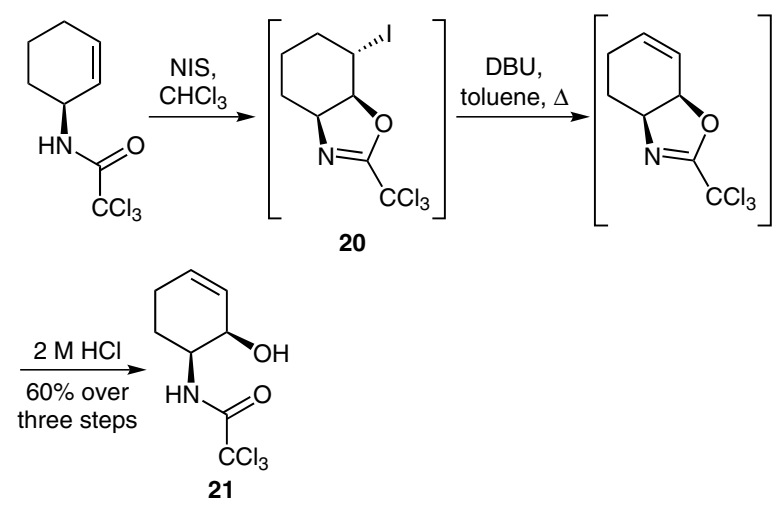

Scheme 9

We then conducted a study on the stereoselective dihydroxylation of allylic alcohol $\mathbf{2 1}$ for the synthesis of dihydroconduramines. ${ }^{29}$ Directed epoxidation with $m$-CPBA gave the $s y n$-isomer 22 in $69 \%$ yield (Scheme 10). Regio- selective hydrolytic ring opening of the epoxide under acidic conditions and removal of the trichloromethylcarbonyl protecting group gave ent-dihydroconduramine $\mathrm{C}-1$ (23) in excellent yield. Dihydroxylation of 21 under Upjohn conditions occurred by a nondirected mechanism ${ }^{30}$ to give triol 24 in $56 \%$ yield as a single stereoisomer (Scheme 10). Removal of the amine protecting group by basic hydrolysis gave dihydroconduramine E-1 (25) in good overall yield.

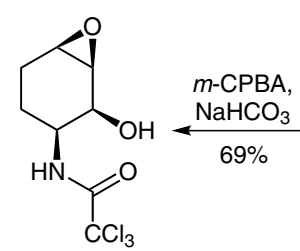

22

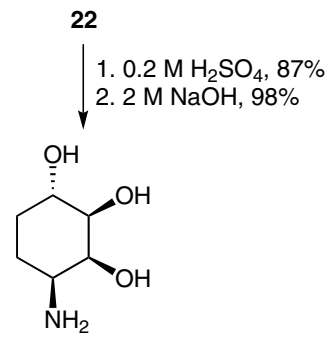

23<smiles>O=C(NC1CCC=CC1O)C1CC(O)[C@H](O)C(O)C1NC(=O)C(Cl)(Cl)Cl</smiles>

21<smiles>[Z4]C[14CH2]O[14C@@H]1[C@@H](O)[C@H](O)[C@H](N)CC[C@H]1O</smiles>

25
Scheme 10

Although only two members of the dihydroconduramine family were prepared by this approach, the study demonstrated how the building blocks generated from our onepot two-step process can be quickly functionalized in a highly stereoselective manner.

As well as carbocycles, $N$-heterocycles were also prepared by using the one-pot two-step process. For example, hydroxylated 3-aminoazepanes, motifs found in natural products and medicinal agents, were prepared by using a combination of the one-pot multi-reaction process and directed oxidations. ${ }^{31}$ Initially, 2-aminoethanol (26) was converted into the allylic alcohol $\mathbf{2 7}$ in seven steps and $53 \%$ overall yield by using a strategy involving alkylation of the amine with 4-bromobut-1-ene, followed by extension of the carbon chain using a one-pot Swern oxidation and a Wittig reaction (Scheme 11). Conversion of alcohol 27 into the allylic trichloroacetimidate, followed by the one-pot Overman rearrangement and RCM reaction with Grubbs' second-generation catalyst gave azepane $\mathbf{2 8}$ in $79 \%$ yield over the three steps. For this version of the onepot two-step process, we found that Grubbs' second-generation catalyst was much faster in completing the RCM reaction than was Grubbs' first-generation catalyst (12 hours versus 96 hours) and led to a more efficient process ( $79 \%$ overall yield versus $49 \%$ overall yield).

Directed epoxidation and regioselective reduction of azepane $\mathbf{2 8}$ followed by deprotection gave amino alcohol $\mathbf{2 9}$, the syn-stereoisomer of the core of balanol, a fungal metabolite and a potent inhibitor of human protein kinase 
C. ${ }^{31}$ Higher analogues, such as 30, were also prepared. Directed dihydroxylation of azepane $\mathbf{2 8}$ with $\mathrm{OsO}_{4}$ and TMEDA gave the all-syn-3-amidoazepane-4,5-diol as a single stereoisomer. Deprotection then gave $\mathbf{3 0}$ in high overall yield. Asymmetric syntheses of azepane $\mathbf{2 8}$ were demonstrated using $(S)$ - and $(R)$-COP-Cl catalysts during the one-pot process to give the $(R)$ - and $(S)$-enantiomers, respectively, both in $92 \%$ enantiomeric excess.

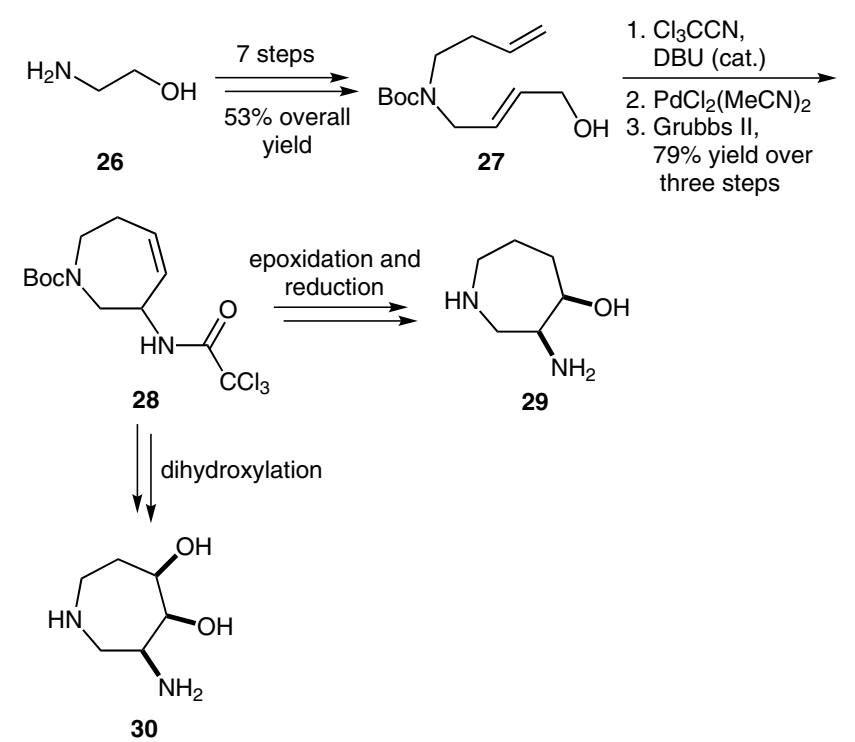

Scheme 11

\subsection{A Directed Overman Rearrangement and Ring-Closing Metathesis Reaction Process}

Having developed both an ether-directed Overman rearrangement and a one-pot two-step process involving this transformation, we wanted to investigate whether these two techniques could be combined to give rapid access to more highly functionalized products. A suitable substrate 32 was prepared in seven steps and $86 \%$ overall yield from $(S)$-glycidol (31; Scheme 12) ${ }^{32,33}$ An important step in this synthetic route involved a highly regioselective ring opening of the epoxide with allylmagnesium bromide and a copper(I) salt to introduce the alkenyl side chain and generate a secondary alcohol group that would ultimately lead to the directing group. Another key stage was the use of the one-pot Swern oxidation and HWE reaction under Masamune-Roush conditions, which permitted the preparation of an $\alpha, \beta$-unsaturated ethyl ester in $99 \%$ yield, with the $E$-isomer as the sole product. ${ }^{33}$ The one-pot ether-directed Overman rearrangement and RCM reaction process was then conducted by using bis(acetonitrile)palladium(II) chloride and Grubbs' first-generation catalyst (both at $10 \mathrm{~mol} \%$ ). ${ }^{1} \mathrm{H}$ NMR spectroscopy of the crude product mixture showed that it consisted of a 10:1 mixture of diastereomers. Column chromatography gave the major diastereomer 33 in $60 \%$ yield from the allylic alcohol 32. Although the level of diastereoselectivity for the directed Overman rearrangement was acceptable, the outcome did not match the levels of induction that we had observed for simpler MOM ether derived allylic trichloroacetimidates. We reasoned that the side-chain alkene might be interfering with effective coordination of the palladium(II) catalyst to the MOM group, as observed with other alkene-derived imidates. ${ }^{32}$

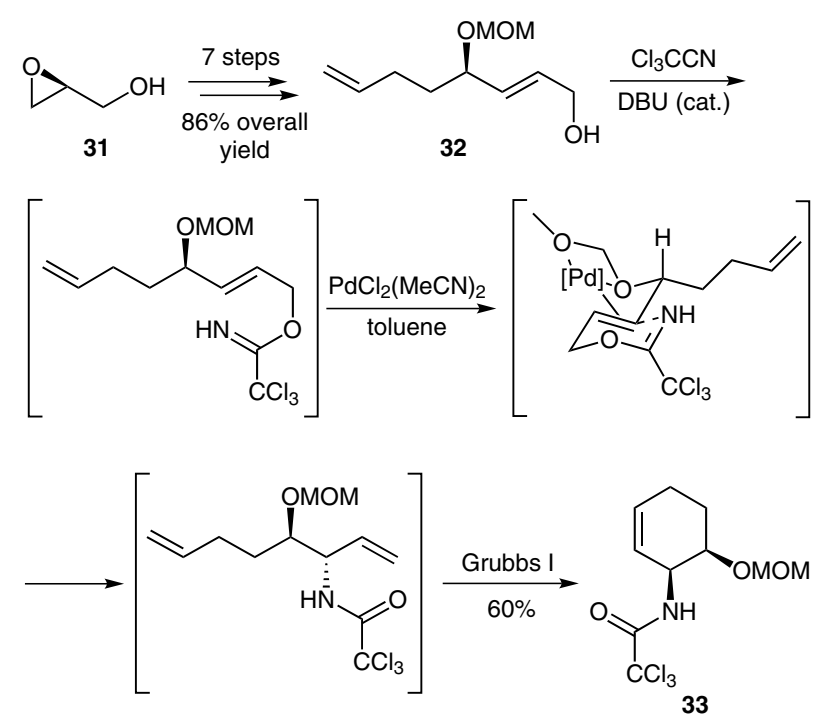

Scheme 12

We then used the carbocyclic amide $\mathbf{3 3}$ in the preparation of 7-deoxypancratistatin analogues bearing a novel syn$(4 \mathrm{a} S, 10 \mathrm{~b} S)$-phenanthridone ring junction (Scheme 13). ${ }^{33}$ (+)-7-Deoxypancratistatin has been shown to have strong in vitro antiproliferative activity against a series of human tumor cell lines and has an excellent therapeutic index in antiviral assays. ${ }^{34} \mathrm{We}$ were therefore interested in preparing novel analogues that might also have significant biological activities. The phenanthridone skeleton was rapidly prepared from amide 33. Hydrolysis of the trichloroacetamide group and coupling with 6-bromopiperonylic acid (34) under standard conditions gave amide 35. A modified Heck reaction of $\mathbf{3 5}$ then allowed formation of the key $\mathrm{C}-\mathrm{C}$ bond to give a $(4 R, 4 \mathrm{a} S, 10 \mathrm{~b} S)$-tetrahydrophenanthridin-6-one that underwent acid-mediated removal of the MOM protecting group to give the alcohol 36 in good overall yield.

We intended to use alcohol $\mathbf{3 6}$ to explore oxidation processes of the cyclohexene ring to generate novel analogues of (+)-7-deoxypancratistatin. ${ }^{33}$ Directed epoxidation of $\mathbf{3 6}$ with $m$-CPBA gave the all-syn-compound 37 as a single diastereomer in $75 \%$ yield. Dihydroxylation using $\mathrm{OsO}_{4}$ and TMEDA proceeded by a nondirected mechanism to give diol $\mathbf{3 8}$ in $90 \%$ yield as a single diastereomer. The structure of this product was confirmed by X-ray crystallography. To better understand the outcomes of these reactions, we explored the likely reacting conformers of compound $\mathbf{3 6}$ by means of density functional theory (DFT) calculations. The optimized structure contained the cyclohexene ring in a partial chair conformation and, because of the cis-ring junction, this created a cavity with the other three rings. We proposed 


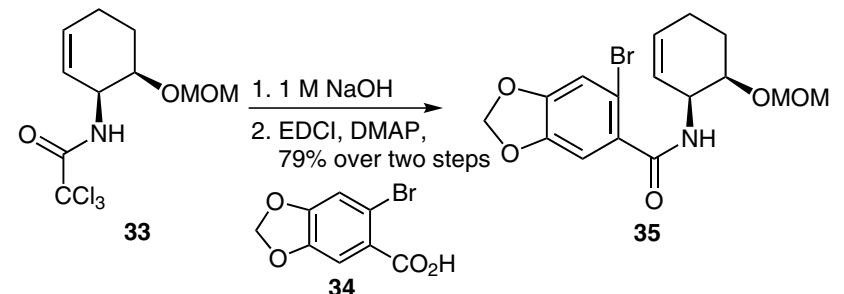

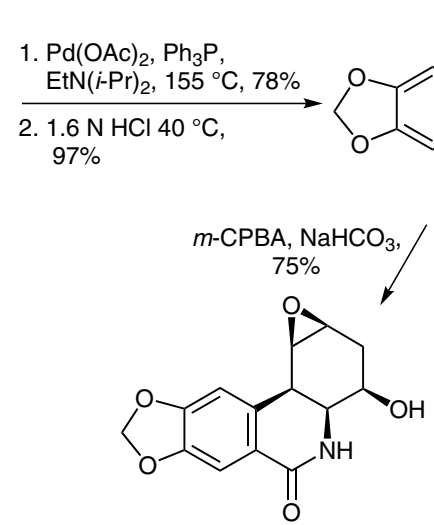

37
Using (2E)-octa-2,7-dien-1-ol (11) to develop this process, we showed that, after the Overman rearrangement and the RCM reaction, heating the reaction mixture to $155^{\circ} \mathrm{C}$ initiated a Kharasch cyclization, resulting in the formation of the corresponding bicyclic [4.3.0] $\gamma$-lactam 8 as a single diastereomer (Scheme 14). ${ }^{39}$

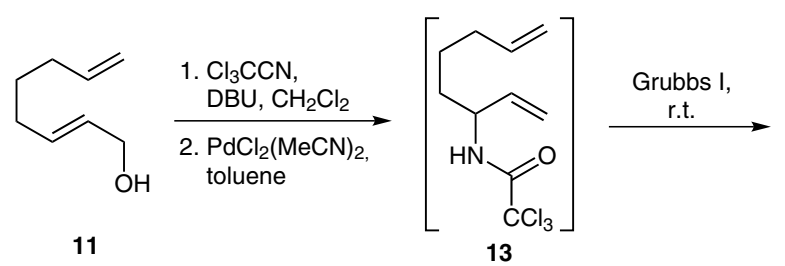<smiles>CC(C)(C)C(=O)NC1C=CCC=C1</smiles>

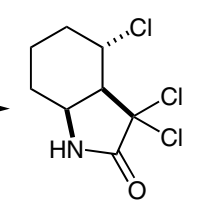

Scheme 14

In our initial development work, we investigated various amounts of catalyst and various reaction temperatures, but all these led to isolation of lactam 8 in yields of $60-70 \%$ over the four steps. However, we found that the addition of molecular sieves to the one-pot process resulted in a significant increase in yield to around $87 \%$. The molecular sieves act as acid scavengers, removing the small amounts of $\mathrm{HCl}$ formed during the high-temperature Kharasch cyclization.

We then extended the scope of the one-pot three-step process to include the preparation of a range of bicyclic $\gamma$-lactams (Scheme 15). ${ }^{39}$ By using the conditions shown in Scheme 14, the bicyclic [3.3.0] lactam 43 was easily prepared in $71 \%$ yield over the four steps. A one-pot synthesis of bicyclic [5.3.0] lactam 44 was also possible, but required a higher loading of Grubbs' first-generation catalyst for the RCM and Kharasch steps ( $25 \mathrm{~mol} \%$ ). We also showed that the asymmetric syntheses of lactams 8 and 43 could be achieved by using commercially available COP$\mathrm{Cl}$ catalysts during the Overman rearrangement. These one-pot processes gave the major enantiomers in 89-94\% ee.

In addition to the synthesis of carbocycle-based bicyclic $\gamma$-lactams, we were also interested in extending this process to include products containing additional heteroatoms. Suitably derived $O$ - and $N$-substituted allylic alcohols 41 and $\mathbf{4 2}$ were prepared from ethylene glycol and glycine, respectively, and, although these did give the corresponding bicyclic [4.3.0] lactams $\mathbf{4 5}$ and 46, the yields over the four steps were generally poor (19-36\%). Frustrated by these results, we examined each step and found that the low yields were due to an inefficient Overman rearrangement in which the activity of the palladium(II) catalyst was suppressed by coordination to the heteroatom and the side-chain alkene. To overcome this 
problem of low yields, we used a thermal Overman rearrangement as part of the one-pot three-step process, and this gave bicyclic [4.3.0] lactams $\mathbf{4 5}$ and $\mathbf{4 6}$ in much higher yields.

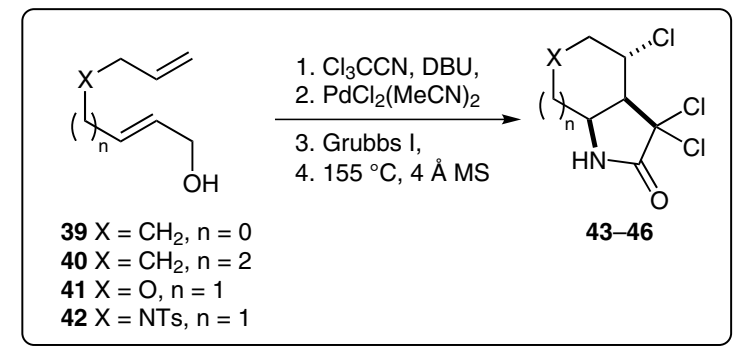<smiles>O=C1NC2CC[C@H](Cl)C2C1(Cl)Cl</smiles>

43, $71 \%$<smiles>O=C1NC2CCCCC(Cl)C2C1(Cl)Cl</smiles>

$44,60 \%$<smiles>O=C1NC2COCC(Cl)C2C1(Cl)Cl</smiles>

$45,52 \%^{a}$

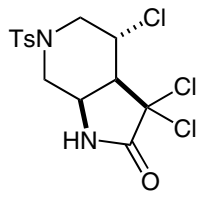

46, $39 \%^{\mathrm{a}}$
Scheme 15 One-pot three-step synthesis of bicyclic lactams. ${ }^{\text {a }}$ Overman rearrangement performed under thermal conditions.

\subsection{A Microwave-Mediated One-Pot Three-Step Process}

Although a thermal Overman rearrangement permitted the one-pot synthesis of bicyclic [4.3.0] lactams $\mathbf{4 5}$ and $\mathbf{4 6}$ in good overall yields, the process suffered the drawback of a long reaction time. ${ }^{39}$ Whereas palladium(II)-catalyzed Overman rearrangements can proceed to completion within a few hours at room temperature, thermal Overman rearrangements can take significantly longer. For example, the thermal Overman rearrangement that led to bicyclic [4.3.0] lactam 46 was performed at $140{ }^{\circ} \mathrm{C}$ and took 136 hours.

As most of the steps of this one-pot process now involved heating, we proposed that performing the entire process in a microwave reactor might accelerate the preparation of the products. ${ }^{40}$ By using silicon carbide passive heating elements (PHEs) to help with the transfer of microwave energy in our optimized solvent, toluene, ${ }^{41,42}$ we conduct-

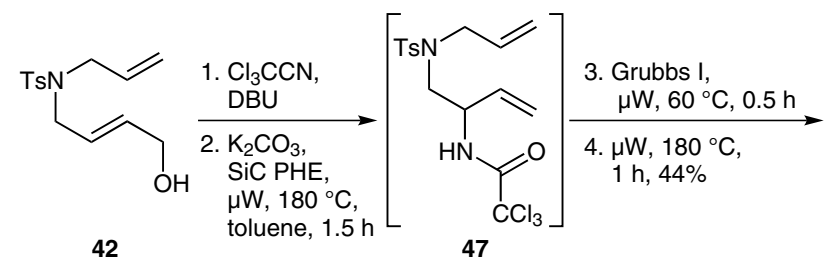<smiles>[13CH3]N1CC2NC(=O)C(Cl)(Cl)[C@@H]2[C@H](Cl)C1</smiles>

46

Scheme 16 One-pot synthesis of lactam 46 with microwave heating ed the entire one-pot three-step process for the preparation of bicyclic [4.3.0] lactam 46 with microwave heating (Scheme 16). We were pleased to find that the entire process could be completed in three hours. We conducted a general study to compare the two approaches for the preparation of bicyclic $\gamma$-lactams and, in all cases, as well as being much faster, microwave heating gave the products more cleanly and more reproducibly than did standard thermal methods.

\section{A One-Pot Three-Step Process Involving a Ring-Closing Enyne Metathesis and a Diels- Alder Reaction}

\subsection{Synthesis of Substrates}

Our next objective was to extend the concept of one-pot multi-reaction processes to include other transformations that would permit the generation of more-complex structures. We felt that this could be achieved simply by changing the side chain of the allylic alcohol from an alkene to an alkyne (Scheme 17). The Overman rearrangement of such a compound should give an allylic trichloroacetamide that would undergo a ring-closing enyne metathesis (RCEYM) reaction. We proposed that the resulting exodiene might then be trapped by a range of dienophiles in a Diels-Alder reaction. This one-pot multi-reaction multiple bond-forming process should allow $\mathrm{C}-1$ amino-substituted bicyclic compounds with up to four contiguous stereogenic centers to be prepared from simple linear allylic alcohols.
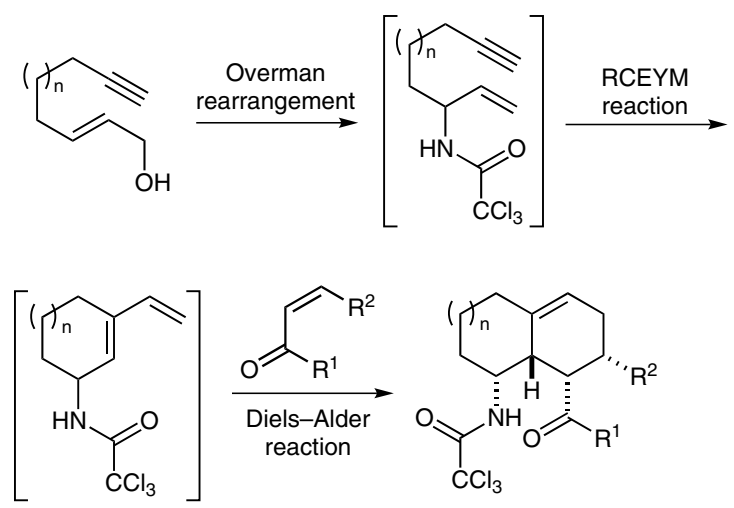

Scheme 17

As with our previous one-pot multi-reaction substrates, we wanted to be able to obtain the alkyne analogues easily and efficiently. Therefore, a similar two-pot synthetic approach was developed (Scheme 18). ${ }^{43}$ Two substrates were initially prepared from pent-4-yn-1-ol (48) and hex5-yn-1-ol (49), respectively. A one-pot Swern oxidation and HWE reaction gave the corresponding $E$ - $\alpha, \beta$-unsaturated esters $\mathbf{5 0}$ and $\mathbf{5 1}$ in very high yields. The next step involved DIBAL-H reduction of the ethyl ester. We were concerned about this stage of the synthesis, as DIBAL-H reduction of alkynes had been reported in the literature. ${ }^{44}$ 
However, at $-78^{\circ} \mathrm{C}$, the ester was cleanly and selectively reduced to give allylic alcohols $\mathbf{5 2}$ and $\mathbf{5 3}$ in excellent overall yields.
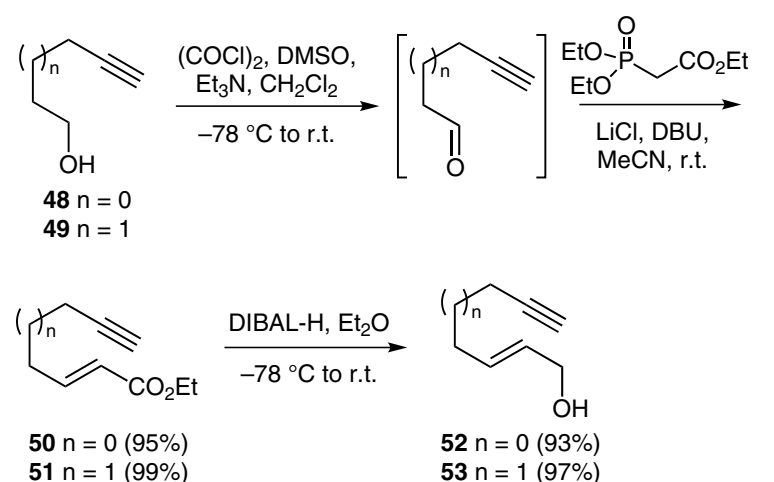

Scheme 18

\subsection{An Unexpected Hydrogen-Bonding-Directed Diels-Alder Reaction}

The one-pot multi-reaction process was then investigated by using (2E)-octa-2-en-7-yn-1-ol (53) with $N$-phenylmaleimide as the dienophile (Scheme 19). ${ }^{43}$ Initially, allylic trichloroacetimidate 54 was prepared under standard conditions. On optimizing the various steps, we found that the most efficient process involved a thermally mediated Overman rearrangement at $140{ }^{\circ} \mathrm{C}$, followed by an RCEYM reaction with Grubbs' first-generation catalyst (10 mol\%) at $75{ }^{\circ} \mathrm{C}$ and, finally, a Diels-Alder reaction with $\mathrm{N}$-phenylmaleimide at $111^{\circ} \mathrm{C}$. This gave the substituted tetralin derivative $\mathbf{5 7}$ in $\mathbf{7 2 \%}$ overall yield from allylic alcohol 53. Furthermore, we were surprised by the isolation of the product as a single diastereomer, as we had ex-

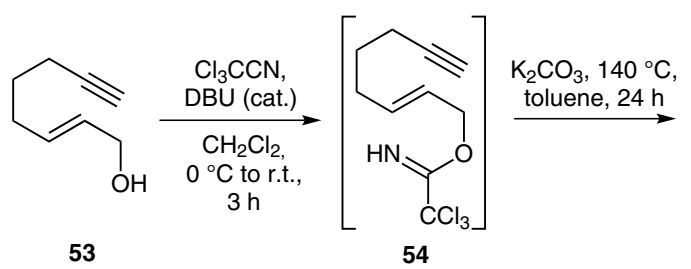

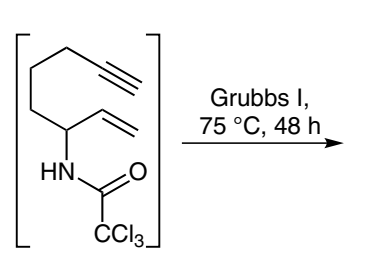

55

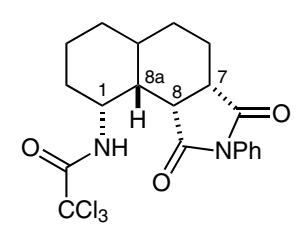

57

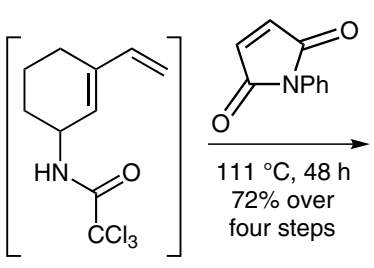

56

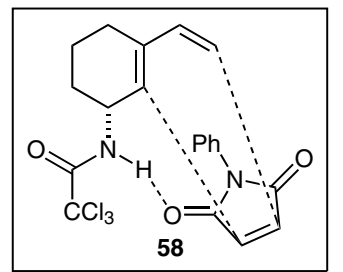

Scheme 19

pected to obtain a mixture of two diastereomeric endoproducts. However, NOE experiments confirmed the exclusive formation of tetralin $\mathbf{5 7}$, with a syn-relationship of the hydrogen atoms at $\mathrm{C}-1, \mathrm{C}-7, \mathrm{C}-8$, and $\mathrm{C}-8 \mathrm{a}$. We suspected that a hydrogen bond between the amide hydrogen and the maleimide oxygen atom might be responsible for directing the Diels-Alder reaction (58; Scheme 19). Evidence of this was found by repeating the Diels-Alder reaction of 56 with $N$-phenylmaleimide in methanol, which gave a 1:1 mixture of the two endo-diastereomers in $87 \%$ isolated yield. Additional evidence was gained from a DFT computational study, which showed that the syntransition state was stabilized by our proposed hydrogen bond with an energy difference of approximately $10 \mathrm{~kJ}$ $\mathrm{mol}^{-1}$.

Note that Overman rearrangement of $\mathbf{5 4}$ during this onepot multi-reaction process could be catalyzed by a palladium(II) complex; however, a high catalyst loading (20 mol\%) was required for an efficient transformation. We believe that the complications involved in the palladium(II)-catalyzed rearrangement are similar to that observed with the imidate intermediates for bicyclic $\gamma$ lactams $\mathbf{4 5}$ and $\mathbf{4 6}$, in that the catalyst coordinates to functional groups in the side chain.

\subsection{Application of the Synthesis for C1-Amino- Substituted Indanes and Tetralins}

The scope of our highly diastereoselective multistep reaction process involving a thermally mediated Overman rearrangement was explored for the two allylic alcohols $\mathbf{5 2}$ and 53 with a range of dienophiles (Scheme 20). ${ }^{43}$ The process gave a diverse series of $\mathrm{C}-1$ amino-substituted partially saturated tetralin and indane structures incorporating a range of functional groups. In all cases, the hydrogen-bonding-directed Diels-Alder reaction generated the final compounds in high diastereoselectivities, permitting the isolation of compounds 59-65 in good yields over the four steps. In this part of the study, we obtained further evidence for hydrogen bonding between the diene and dienophile by using nonsymmetric dienophiles, such as methyl acrylate. As well as producing adducts $\mathbf{6 1}$ and $\mathbf{6 5}$ in excellent diastereoselectivities, a single regioisomer was formed exclusively via the hydrogen-bonded intermediate. Interestingly, cyclohexadiene $\mathbf{6 2}$ was generated from the reaction of $\mathbf{5 6}$ with 1,4-naphthoquinone, presumably by air oxidation of the initial Diels-Alder adduct.

\subsection{Development of a Two-Pot Reaction Process}

Having developed our one-pot multistep reaction process, we wished to extend it to include additional reactions. The unexpected formation of cyclohexadiene $\mathbf{6 2}$ suggested that one obvious extension might be the Diels-Alder reaction of the cyclic dienes with a range of 1,4-quinones or alkynes to form the cyclohexadienes with subsequent oxidation to give the corresponding aromatic compound (Scheme 21). In particular, we were interested to discover 


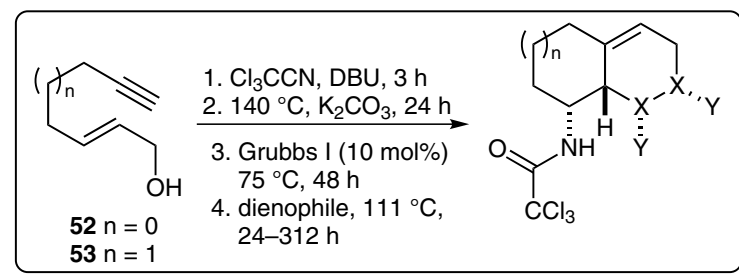

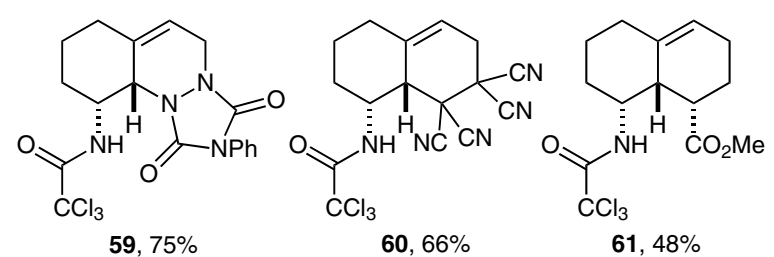<smiles>C[C@]12CCCC(=CCC3=C1C(=O)c1ccccc1C3=O)[C@H]2NC(=O)C(F)(F)F</smiles>
62, $61 \%$

$60,66 \%$<smiles>O=C1[C@H]2CC=C3CC[C@H](NC(=O)C(Cl)(Cl)Cl)[C@@H]3[C@@H]2C(=O)N1c1ccccc1</smiles>

$63,62 \%{ }^{\mathrm{a}}$

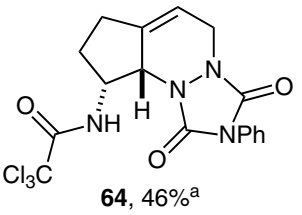<smiles>COC(=O)[C@H]1CCC=C2CC[C@H](NC(=O)C(C)(C)C)[C@H]21</smiles>

Scheme 20 Multistep synthesis of indanes and tetralins. ${ }^{\text {a }}$ The DielsAlder reactions were performed at $75^{\circ} \mathrm{C}$

whether oxidation conditions were compatible with the preceding steps in a one-pot process. An additional motivation for developing this extended process was that the aromatic indane and tetralin products are commonly found in a wide range of important pharmaceutical agents. $^{45-47}$

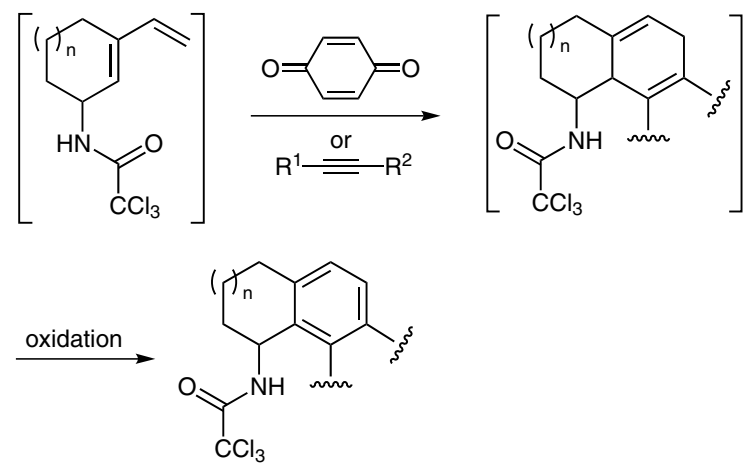

Scheme 21

Our initial attempts to extend the one-pot multi-reaction process to include an oxidation step after a Diels-Alder reaction with 1,4-benzoquinone were promising, giving the final product in good yields. However, in trying to develop a general process for the preparation of a diverse library of indanes and tetralins, we found that the reaction mixtures were generally difficult to purify, resulting in

moderate yields over the five steps. We therefore decided to generate these privileged structures by using a two-pot multi-reaction strategy. The first one-pot process involved the Overman rearrangement and an RCEYM reaction to give the cyclic exo-dienes. This was followed by a second one-pot process that involved the Diels-Alder reaction and the oxidation step.

A one-pot multistep process was quickly developed for the preparation of carbocyclic dienes 56 and 66, which were obtained in excellent yields over the three steps (Scheme 22). ${ }^{48}$ During our early investigations of the Diels-Alder reactions of $\mathbf{5 6}$ with alkynes, we found that only a limited number of particularly electron-deficient dienophiles provided adducts in good yields. Therefore, in an attempt to broaden the diversity of compounds formed during this process, we also investigated the synthesis of heterocyclic dienes 67 and 68. Preparation of the required allylic alcohols, subsequent imidate formation, and Overman rearrangement proceeded in high yields without any problems. However, slow RCEYM reactions were observed, leading to low overall yields. To overcome this problem, we added octa-1,7-diene to these reactions to generate ethylene in situ. ${ }^{49}$ For the syntheses of both dihydropyran 67 and tetrahydropyridine 68, this modification gave greatly improved yields at standard catalyst loadings.

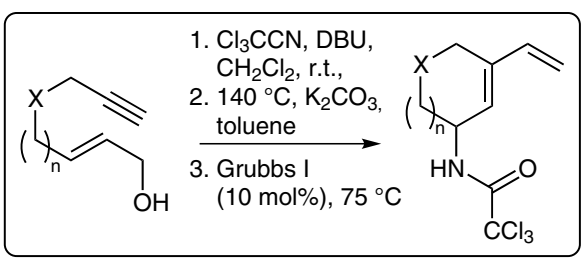

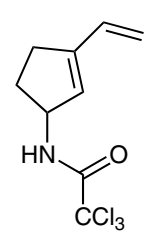

66, $71 \%$<smiles>C/C=C\C1=CC(NC(=O)C(F)(F)Cl)CCC1</smiles>

$56,86 \%$<smiles>C=CC1=CC(NC(=O)C(Cl)(Cl)Cl)COC1</smiles>

$67,46 \%^{\mathrm{a}}$<smiles>C=CC1=CC(NC(=O)C(F)(F)Cl)C[Al]C1</smiles>

$68,40 \%{ }^{a, b}$
Scheme 22 a The RCEYM reaction was performed at $90{ }^{\circ} \mathrm{C}$ in the presence of octa-1,7-diene. ${ }^{\mathrm{b}}$ The RCEYM reaction was performed by using the Hoveyda-Grubbs second-generation catalyst (5 mol\%).

In developing the second one-pot process, we found, as predicted, that relatively few alkynes would undergo a Diels-Alder reaction with dienes 56 and 66-68. ${ }^{48}$ Nevertheless, the electron-deficient alkynes diethyl acetylenedicarboxylate and methyl propiolate did give the corresponding dihydrobenzenes in good yields (Scheme 23). Completion of the one-pot process by oxidizing these intermediates with DDQ gave the corresponding indanes and tetralins in good yields over the two steps. As in previous Diels-Alder reactions of dienes 56 and 66, reaction with nonsymmetrical dienophiles gave the corresponding products (e.g., 72) as single regioisomers, again through a hydrogen-bonding-directed process. 


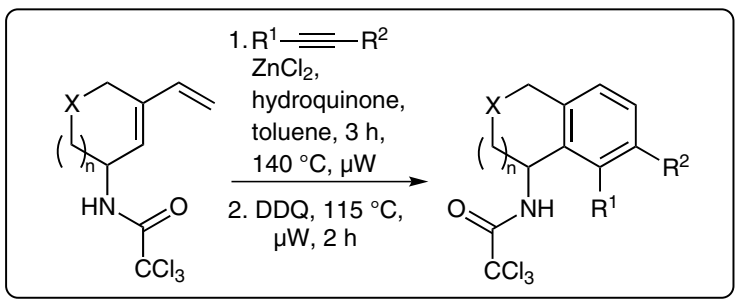<smiles>CCOC(=O)c1ccc2c(c1C(=O)OCC)C(NC(=O)C(Cl)(Cl)Cl)CC2</smiles><smiles>CCOC(=O)c1ccc2c(c1OCC)C(NC(=O)C(Cl)(Cl)Cl)CCC2</smiles>

69, $71 \%$

$70,58 \%$<smiles>CCOC(=O)c1ccc2c(c1OCC)C(NC(=O)C(C)(C)C)CN([Al])C2</smiles>

$71,48 \%$<smiles>COC(=O)c1cccc2c1C(NC(=O)C(Cl)(Cl)C(F)(F)Cl)CCC2</smiles>

$72,66 \%^{a}$

Scheme 23 a Both steps were performed under standard thermal conditions in a Schlenk tube

The Diels-Alder reaction of the cyclic exo-dienes with 1,4-quinones was found to be more general, permitting the preparation of a diverse library of novel indanes and tetralins (Scheme 24).$^{48}$ In this one-pot two-step process, a Diels-Alder reaction under standard thermal conditions was found to be more efficient with 1,4-benzoquinones. The oxidation step proceeded more readily with manganese dioxide as oxidant, except for heterocyclic analogues (e.g., 75 and 77), where benzylic oxidation was also observed. In these cases, DDQ provided the aromatic analogues in good yields. Furthermore, we found that the Diels-Alder reaction of the dienes with nonsymmetrical 1,4-quinones, such as 2-tert-butyl-1,4-benzoquinone, gave the products as single regioisomers (e.g., 76 and 77).

We wanted to expand the scope of this process to include the synthesis of heteroaromatic compounds through a Diels-Alder reaction of dienes 56 and $\mathbf{6 6}$ with electrondeficient nitriles (Scheme 25) ${ }^{48} \mathrm{We}$ proposed that the inherent polarization of the nitriles would result in a regioselective reaction to give dihydropyridines that could then be oxidized to the corresponding pyridines. ${ }^{48}$ Examination of the ${ }^{1} \mathrm{H}$ NMR spectrum of the crude reaction mixture from the Diels-Alder reaction of $\mathbf{5 6}$ with $p$ toluenesulfonyl cyanide showed that significant quantities of the pyridine were already present. Therefore, subsequent reactions were performed at slightly higher temperatures $\left(160^{\circ} \mathrm{C}\right.$ instead of $\left.115^{\circ} \mathrm{C}\right)$ to give pyridine 80 in $54 \%$ yield without the need for an oxidation step. Reaction with other nitriles, such as ethyl cyanoformate or trichloroacetonitrile, gave the corresponding pyridines directly in good yields and as single regioisomers. Aromatization of the dihydropyridine formed from reaction of $\mathbf{5 6}$

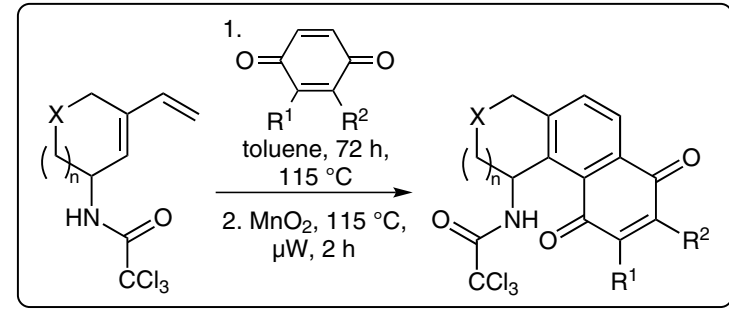<smiles>O=C1C=CC(=O)c2c1ccc1c2C(NC(=O)C(F)(Cl)Cl)CC1</smiles><smiles>O=C1C=CC(=O)c2c1ccc1c2C(NC(=O)C(F)(F)Cl)CCC1</smiles>

$73,75 \%$<smiles></smiles>

$\mathbf{7 4}, 66 \%$

$75,48 \%{ }^{a}$<smiles>CC(C)(C)C(=O)NC1CCc2ccc3c(c21)C(=O)C=C(C(C)(C)C)C3=O</smiles>

76, $68 \%$<smiles>CC(C)(C)C1=CC(=O)c2c(ccc3c2C(NC(=O)C(F)(Cl)Cl)COC3)C1=O</smiles><smiles>O=C1c2ccccc2C(=O)c2c1ccc1c2C(NC(=O)C(F)(F)C(F)(F)F)CCC1</smiles>

$78,54 \%^{a}$

Scheme $24{ }^{\text {a }}$ Oxidation step performed by using DDQ

with trichloroacetonitrile proceeded by loss of $\mathrm{HCl}$ followed by a 1,3-hydride shift to give the 2-(dichloromethyl)pyridine 81 in $67 \%$ yield.

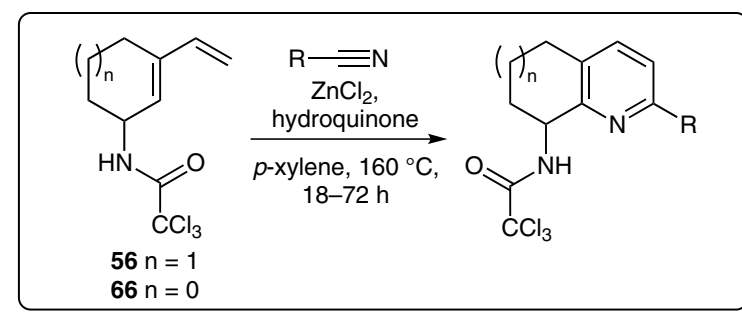<smiles>O=C(NC1CCc2ccc(F)nc21)C(F)(Cl)Cl</smiles>

$79,58 \%^{\mathrm{a}}$<smiles>O=C(NC1CCCc2ccc(C(Cl)Cl)nc21)C(F)(F)Cl</smiles>

$81,67 \%$<smiles>O=C(NC1CCCc2ccc(Br)nc21)C(F)(F)Cl</smiles>

$80,54 \%$<smiles>CCOc1ccc2c(n1)C(NC(=O)C(C)(C)C)CCC2</smiles>

$82,40 \%$
Scheme $25{ }^{\text {a }}$ The reaction was performed at $125^{\circ} \mathrm{C}$ 
Overall, despite the limited reactivity of the cyclic exo-dienes with some disubstituted alkynes, a novel and diverse library of C-1 amino-derived indanes and tetralins, incorporating a range of substituents and functional groups, were prepared from electron-deficient alkynes, 1,4-quinones, and nitriles.

\section{$5 \quad$ Conclusions}

With the continual drive by academic and industrial chemists to generate complex intermediates and targets from simple starting materials, we believe that the development and utilization of one-pot, multi-reaction, multiple bond-forming processes will find widespread application in synthetic chemistry. New discoveries continue to be reported, such as the elegant synthesis of 3,4dihydroquinolinones recently described by Lautens and co-workers, which involved the first one-pot, triple metalcatalyzed process. ${ }^{50}$

In our own research, we have been able to show that reactions involving palladium(II) and ruthenium(II) catalysts can be performed in a single flask. We have also been able to combine these processes with additional multiple bondforming reactions in which one of the transition-metal complexes catalyzes a second transformation. Furthermore, we have been able to extend these processes to include Diels-Alder reactions, resulting in the rapid generation of significantly more-complex structures with up to four contiguous stereogenic centers. However, as demonstrated by our attempts to engineer a general onepot synthesis of indanes and tetralins from alkyne-derived allylic trichloroacetimidates, there are limitations to this approach. Only certain types of reaction can be combined to permit highly efficient formation of advanced intermediates. Nevertheless, as we continue to improve our understanding of these limitations, the development of synthetic routes that utilize one-pot multi-reaction processes will accelerate advances in medicinal chemistry and in total synthesis.

\section{Acknowledgment}

We would like to thank all our co-workers who were involved in this program of research, particularly Andrew Jamieson, Kate Fanning, Michael Swift, Ahmed Zaed, Fiona McGonagle, and Sajjad Ahmad. Funding from the University of Glasgow, EPSRC (DTA award), and the Schering-Plough Corporation is gratefully acknowledged.

\section{References}

(1) For general reviews, see: (a) Tietze, L. F. Chem. Rev. 1996, 96, 115. (b) Nicolaou, K. C.; Edmonds, D. J.; Bulger, P. G. Angew. Chem. Int. Ed. 2006, 45, 7134. (c) Chapman, C. J.; Frost, C. G. Synthesis 2007, 1.

(2) For more recent and specific reviews, see: (a) Zhou, J. Chem. Asian J. 2010, 5, 422. (b) Ruiz, M.; López-Alvarado, P.; Giorgi, G.; Menéndez, J. C. Chem. Soc. Rev. 2011, 40, 3445. (c) Liu, Y.; Wan, J.-P. Org. Biomol. Chem. 2011, 9,
6873. (d) Pellissier, H. Adv. Synth. Catal. 2012, 354, 237. (e) Galeštokova, Z.; Šebesta, R. Eur. J. Org. Chem. 2012, 6688. (f) Foster, R. A. A.; Willis, M. C. Chem. Soc. Rev. 2013, 42,63 .

(3) Vaxelaire, C.; Winter, P.; Christmann, M. Angew. Chem. Int. Ed. 2011, 50, 3605.

(4) Clarke, P. A.; Santos, S.; Martin, W. H. C. Green Chem. 2007, 9,438

(5) (a) Ishikawa, H.; Suzuki, T.; Hayashi, Y. Angew. Chem. Int. Ed. 2009, 48, 1304. (b) Ishikawa, H.; Suzuki, T.; Orita, H.; Uchimaru, T.; Hayashi, Y. Chem. Eur. J. 2010, 16, 12616. (c) Ishikawa, H.; Honma, M.; Hayashi, Y. Angew. Chem. Int. Ed. 2011, 50, 2824. (d) Ishikawa, H.; Bondzic, B. P.; Hayashi, Y. Eur. J. Org. Chem. 2011, 6020.

(6) Hayashi, Y.; Umemiya, S. Angew. Chem. Int. Ed. 2013, 52, 3450 .

(7) Overman, L. E.; Carpenter, N. E. Org. React. (Hoboken, NJ, U. S.) 2005, 66, 1; and references therein.

(8) Jamieson, A. G.; Sutherland, A. Org. Biomol. Chem. 2005, 3,735 .

(9) (a) Jamieson, A. G.; Sutherland, A. Org. Biomol. Chem. 2006, 4, 2932. (b) Jamieson, A. G.; Sutherland, A. Tetrahedron 2007, 63, 2123.

(10) (a) Fanning, K. N.; Jamieson, A. G.; Sutherland, A. Org. Biomol. Chem. 2005, 3, 3749. (b) Swift, M. D.; Sutherland, A. Org. Biomol. Chem. 2006, 4, 3889. (c) Swift, M. D.; Sutherland, A. Tetrahedron Lett. 2007, 48, 3771. (d) Swift, M. D.; Sutherland, A. Tetrahedron 2008, 64, 9521.

(11) Zaed, A. M.; Sutherland, A. Org. Biomol. Chem. 2010, 8, 4394.

(12) Zaed, A. M.; Sutherland, A. Org. Biomol. Chem. 2011, 9, 8030 .

(13) Calder, E. D. D.; Zaed, A. M.; Sutherland, A. J. Org. Chem. 2013, 78, 7223 .

(14) Daly, M.; Gill, K.; Sime, M.; Simpson, G. L.; Sutherland, A. Org. Biomol. Chem. 2011, 9, 6761.

(15) Jamieson, A. G.; Sutherland, A. Org. Lett. 2007, 9, 1609.

(16) (a) Donohoe, T. J.; Blades, K.; Helliwell, M.; Moore, P. R.; Winter, J. J. G. J. Org. Chem. 1999, 64, 2980. (b) Donohoe, T. J.; Blades, K.; Moore, P. R.; Waring, M. J.; Winter, J. J. G.; Helliwell, M.; Newcombe, N. J.; Stemp, G. J. Org. Chem. 2002, 67, 7946. (c) Donohoe, T. J. Synlett 2002, 1223.

(17) O’Brien, P.; Childs, A. C.; Ensor, G. J.; Hill, C. L.; Kirby, J. P.; Dearden, M. J.; Oxenford, S. J.; Rosser, C. M. Org. Lett. 2003, 5, 4955.

(18) Nagashima, H.; Wakamatsu, H.; Ozaki, N.; Ishii, T.; Watanabe, M.; Tajima, T.; Itoh, K. J. Org. Chem. 1992, 57, 1682.

(19) Cassayre, J.; Dauge, D.; Zard, S. Z. Synlett 2000, 471.

(20) Cardillo, G.; Orena, M.; Sandri, S. J. Chem. Soc., Chem. Commun. 1983, 1489.

(21) Swift, M. D.; Sutherland, A. Org. Lett. 2007, 9, 5239.

(22) Ireland, R. E.; Norbeck, D. W. J. Org. Chem. 1985, 50, 2198.

(23) Blanchette, M. A.; Choy, W.; Davis, J. T.; Essenfeld, A. P.; Masamune, S.; Roush, W. R.; Sakai, T. Tetrahedron Lett. 1984, 25, 2183.

(24) (a) Grubbs, R. H. Handbook of Metathesis 2003. (b) Wilson, G. O.; Porter, K. A.; Weissman, H.; White, S. R.; Sottos, N. R.; Moore, J. S. Adv. Synth. Catal. 2009, 351, 1817.

(25) (a) Stevens, A. M.; Richards, C. J. Organometallics 1999, 18, 1346. (b) Nomura, H.; Richards, C. J. Chem. Eur. J. 2007, 13, 10216. (c) Nomura, H.; Richards, C. J. Org. Lett. 2009, 11, 2892.

(26) (a) Overman, L. E.; Owen, C. E.; Pavan, M. M.; Richards, C. J. Org. Lett. 2003, 5, 1809. (b) Anderson, C. E.; Overman, L. E. J. Am. Chem. Soc. 2003, 125, 12412. (c) Anderson, C. E.; 
Kirsch, S. F.; Overman, L. E.; Richards, C. J.; Watson, M. P. Org. Synth. 2007, 84, 148.

(27) Swift, M. D. Ph.D. Thesis; University of Glasgow: UK, 2009.

(28) Zaed, A. M.; Swift, M. D.; Sutherland, A. Org. Biomol. Chem. 2009, 7, 2678.

(29) Ahmad, S.; Thomas, L. H.; Sutherland, A. Org. Biomol. Chem. 2011, 9, 2801

(30) VanRheenen, V.; Kelly, R. C.; Cha, D. Y. Tetrahedron Lett. 1976, 17, 1973

(31) Ahmad, S.; Sutherland, A. Org. Biomol. Chem. 2012, 10, 8251

(32) Swift, M. D.; Donaldson, A.; Sutherland, A. Tetrahedron Lett. 2009, 50, 3241.

(33) Ahmad, S.; Swift, M. D.; Farrugia, L. J.; Senn, H. M.; Sutherland, A. Org. Biomol. Chem. 2012, 10, 3937.

(34) (a) Pettit, G. R.; Gaddamidi, V.; Herald, D. L.; Singh, S. B.; Cragg, G. M.; Schmidt, J. M.; Boettner, F. E.; Williams, M.; Sagawa, Y. J. Nat. Prod. 1986, 49, 995. (b) Pettit, G. R.; Pettit, G. R. III.; Backhaus, R. A.; Boyd, M. R.; Meerow, A. W. J. Nat. Prod. 1993, 56, 1682. (c) Gabrielsen, B.; Monath, T. P.; Huggins, J. W.; Kefauver, D. F.; Pettit, G. R.; Groszek, G.; Hollingshead, M.; Kirsi, J. J.; Shannon, W. M.; Shubert, E. M.; DaRe, J.; Ugarkar, B.; Ussery, M. A.; Phelan, M. J. J. Nat. Prod. 1992, 55, 1569.

(35) Kharasch, M. S.; Jensen, E. V.; Urry, W. H. Science 1945, $102,128$.

(36) Schmidt, B.; Pohler, M. J. Organomet. Chem. 2005, 690, 5552.

(37) (a) Edlin, C. D.; Faulkner, J.; Quayle, P. Tetrahedron Lett. 2006, 47, 1145. (b) Edlin, C. D.; Faulkner, J.; Fengas, D.; Helliwell, M.; Knight, C. K.; House, D.; Parker, J.; Preece,
I.; Quayle, P.; Raftery, J.; Richards, S. N. J. Organomet. Chem. 2006, 691, 5375 .

(38) Seigal, B. A.; Fajardo, C.; Snapper, M. L. J. Am. Chem. Soc. 2005, 127, 16329.

(39) McGonagle, F. I.; Brown, L.; Cooke, A.; Sutherland, A. Org. Biomol. Chem. 2010, 8, 3418.

(40) McGonagle, F. I.; Brown, L.; Cooke, A.; Sutherland, A. Tetrahedron Lett. 2011, 52, 2330.

(41) Kappe, C. O. Angew. Chem. Int. Ed. 2004, 43, 6250.

(42) Kremsner, J. M.; Kappe, C. O. J. Org. Chem. 2006, 71, 4651.

(43) Grafton, M. W.; Farrugia, L. J.; Senn, H. M.; Sutherland, A. Chem. Commun. 2012, 48, 7994.

(44) (a) Gensler, W. J.; Bruno, J. J. J. Org. Chem. 1963, 28, 1254. (b) Eisch, J. J.; Kaska, W. C. J. Am. Chem. Soc. 1966, 88, 2213.

(45) (a) Graul, A.; Castaner, J. Drugs Future 1998, 23, 903. (b) Sterling, J.; Veinberg, A.; Lerner, D.; Goldenberg, W.; Levy, R.; Youdim, M.; Finberg, J. J. Neural Transm., Suppl. 1998, 52, 301.

(46) (a) Koe, B. K.; Weissman, A.; Welch, W. M.; Browne, R. G. J. Pharmacol. Exp. Ther. 1983, 226, 686. (b) Welch, W. M.; Kraska, A. R.; Sarges, R.; Koe, B. K. J. Med. Chem. 1984, 27, 1508.

(47) For example, see: Adams, C.; Papillon, J.; Ksandar, G. M. US 2009/182007, 2009.

(48) Grafton, M. W.; Farrugia, L. J.; Sutherland, A. J. Org. Chem. 2013, 78, 7199 .

(49) Fustero, S.; Bello, P.; Miró, J.; Simón, A.; del Pozo, C. Chem. Eur. J. 2012, 18, 10991.

(50) Zhang, L.; Sonaglia, L.; Stacey, J.; Lautens, M. Org. Lett. 2013, 15, 2128. 